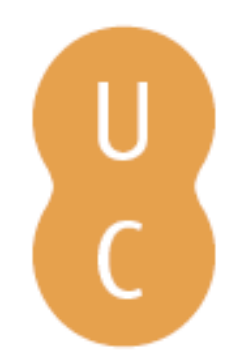

\title{
pommalina
}

\section{Cultura Clássica em Um deus passeando pela brisa da tarde de Mário de Carvalho}

Autor(es): $\quad$ Mendes, António Manuel Gonçalves

Publicado por: Imprensa da Universidade de Coimbra

URL

persistente: URI:http://hdl.handle.net/10316.2/37031

DOI: $\quad$ DOI:http://dx.doi.org/10.14195/978-989-26-0548-7_11

Accessed : $\quad$ 26-Apr-2023 16:03:09

A navegação consulta e descarregamento dos títulos inseridos nas Bibliotecas Digitais UC Digitalis, UC Pombalina e UC Impactum, pressupõem a aceitação plena e sem reservas dos Termos e Condições de Uso destas Bibliotecas Digitais, disponíveis em https://digitalis.uc.pt/pt-pt/termos.

Conforme exposto nos referidos Termos e Condições de Uso, o descarregamento de títulos de acesso restrito requer uma licença válida de autorização devendo o utilizador aceder ao(s) documento(s) a partir de um endereço de IP da instituição detentora da supramencionada licença.

Ao utilizador é apenas permitido o descarregamento para uso pessoal, pelo que o emprego do(s) título(s) descarregado(s) para outro fim, designadamente comercial, carece de autorização do respetivo autor ou editor da obra.

Na medida em que todas as obras da UC Digitalis se encontram protegidas pelo Código do Direito de Autor e Direitos Conexos e demais legislação aplicável, toda a cópia, parcial ou total, deste documento, nos casos em que é legalmente admitida, deverá conter ou fazer-se acompanhar por este aviso.

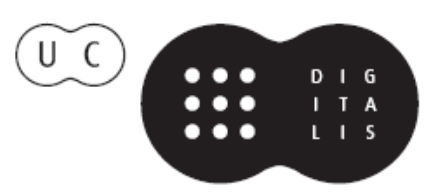


do Tempo e da História

- Mário de Carvalho e a reflexáo metaficcional sobre o futuro do romance - Sátiva e o cepticismo: configuração de personagens em Mário de Carvalho - Escrever tem arte e tem segredos... Era bom que trocássemos umas ideias sobre o assunto - O processo criativo em Era bom que trocássemos umas ideias sobre o assunto - Intertextualidade e metaficção em Fantasia para dois Coronéis e uma Piscina, de Mário de Carvalho - Trimalquiāo, os coronéis e a piscina: retrato impiedoso de um pais em crise $\bullet A$ Paixão do Conde de Fróis: paródia e subversão • "Como dizia o outro": a presença dos Clássicos em Mário de Carvalho - Cultura Clássica em Um

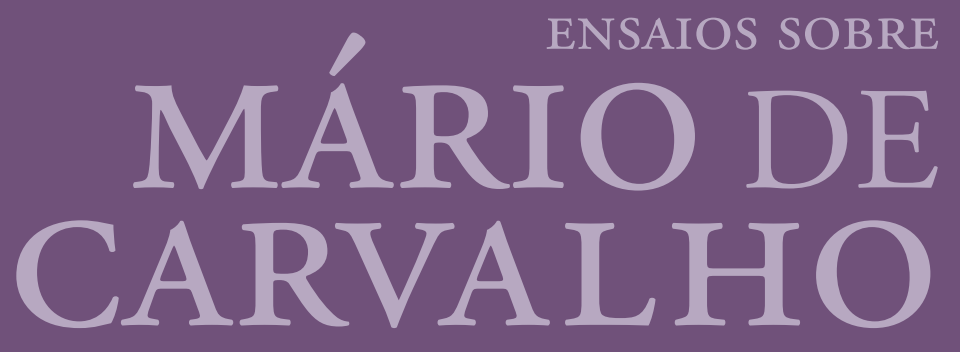

Maria de Fátima Silva Tereza Virgínia Ribeiro Barbosa COORD. IMPRENSA DA UNIVERSIDADE DE COIMBRA COIMBRA UNIVERSITY PRESS

elemento mouro como simbolo de alteridade $e$ barbárie em Um deus passeando pela brisa da 


\section{Cultura Clássica em Um deus passeando pela brisa da tarde de Mário de Carvalho}

António Manuel Gonçalves Mendes

Universidade de Aveiro 
(Página deixada propositadamente em branco) 
Forçado ao exílio pela cidade que havia servido com extrema dedicação, Lúcio Valério Quíncio vive agora um amargo ócio longe dos afazeres da governação. Nesta como em outras situaçóes da vida, este é o preço a pagar pela incompreensão e pela inveja.

Protagonista do romance Um Deus Passeando pela Brisa da Tarde ${ }^{1}$, Lúcio foi duúnviro por duas vezes numa cidade do sul da Hispânia, na região da Lusitânia, de nome Tarcisis, nos tempos do Imperador Marco Aurélio (121-180 d.C.). Este morrera entretanto, e, no capítulo I, aparece-nos um Lúcio profundamente desencantado, remetendo-nos para aquilo que "se adivinha ser um começo «in ultimas res» da matéria que vai seguir-se" 2 e que acontece, pelo menos em parte, no Império do seu filho Cómodo (161-192 d.C.).

O romance desenvolve-se sobre dois alicerces fundamentais: por um lado, a figura mítica do imperador-filósofo, Marco Aurélio, intimamente ligada à figura de Lúcio; por outro, a expansáo do cristianismo por todas as regióes do Império, de que Tarcisis não é excepção. A ligação entre estes dois pontos é feita através do desenvolvimento da história de amor entre Lúcio, magistrado do Império, e Iunia Cantaber, uma patrícia convertida ao cristianismo.

É, curiosamente, essa paixão de Lúcio por Iunia - um, representante da romanidade, outro, pertencente a uma "seita" atentatória desses valores, crente no Deus único - é essa paixão, dizia que o lança para fora da cidade, para a sua antiga uilla que havia sido destruída e maculada por hordas de bárbaros esfomeados.

Personagem-narrador, Lúcio, na sua primeira aparição no início do romance, sofre pelo desterro, pelo sentimento de inutilidade em que se vê, obviado, apenas, pela leitura, pelo consolo dos clássicos:

Brilha o céu, tarda a noite, o tempo é lerdo, a vida baça, o gesto flácido. Debaixo de sombras irisadas, leio e releio os meus livros, passeio, rememoro, devaneio, pasmo, bocejo dormito, deixo-me envelhecer. Não consigo comprazer-me desta mediocridade dourada, pese o convite e o consolo do poeta que a acolheu. Também a mim, como ao Orador, amarga o ócio, quando o negócio foi proibido.

* Este artigo corresponde, no essencial, ao publicado nas Actas do III Colóquio Clássico, realizado na Universidade de Aveiro, nos dias 22 e 23 de Abril de 1999, sob a coordenação de João Manuel Nunes Torrão.

${ }^{1}$ Carvalho ${ }^{4} 1996$. Todas as citações serão feitas a partir desta edição.

2 Seixo 1995. 
Os dias arrastam-se, Marco Aurélio viveu, Cómodo impera, passei o que passei, peno longe, como ser feliz? (13).

Lúcio vive numa aparente quietação, que não é mais do que o otium clássico, propiciador da Humanitas. Proibido de exercer o negotium, aproveita, pelo menos, para possibilitar ao espírito a disponibilidade para se entregar à reflexão, à meditação ${ }^{3}$, bem de acordo com o princípio horaciano da aurea mediocritas ${ }^{4}$. No princípio do romance, porém, a um fim de tarde agradável corresponde um narrador envelhecido, marcado pela monotonia, procurando, de novo, ser feliz.

\section{Do estoicismo de Lúcio}

Há, portanto, um firme propósito de recuperar um estado de espírito de tranquilidade interior, de moderação e do completo domínio de si próprio, de acordo com os preceitos do estoicismo. Lúcio confessa, aliás, a sua simpatia por esta corrente filosófica, quando, no capítulo XVIII, perante o facto de ter de julgar o grupo de cristáos, onde pontifica Iunia, sua apaixonada, e depois de equacionar o suicídio, declara:

Iria eu atraiçoar derradeiramente o lema de Epicteto que sempre quisera - com tanto insucesso - adoptar como norma de vida: «tem-te! Aguenta!» (287).

Nesta fórmula - sustine et abstine - que Aulo Gélio 5 atribui a Epicteto, resume-se a doutrina moral dos Estóicos.

Por outras palavras, o ideal do sábio estóico consiste em ter completo domínio de si, ser autosuficiente (autárcheia); atingir um estado de imperturbabilidade, a apátheia ('apatia'), que é condiçâo indispensável para lograr a serenidade da alma e a liberdade, características do sábio e base da sua felicidade; e evitar a dor, a ataraxía, conceito no qual se consubstancia

3 Cf. Buescu 1979: 42.

4 Horácio, Carmina 2.10.5-8: Auream quisquis mediocritatem/ diligit, tutus caret obsoleti/sordibus tecti, caret inuidendal sobrius aula.

5 Aulo Gélio, Noct. Att. 17.19.6: «Itaque, inquit, si quis haec duo uerba cordi habeat eaque sibi imperando atque obseruando curet, is erit pleraque inpeccabilis uitamque uiuet tranquillissimam». Verba duo haec dicebat: $\alpha$ vé $\chi \omega$ et $\alpha \dot{\pi} \chi \varepsilon_{\chi} \omega$. 
a essência da felicidade e que consiste em manter-se impassível perante os sofrimentos físicos e morais, as enfermidades, a morte, os bens da fortuna, as opinióes dos homens... Estas são as bases da vida virtuosa e feliz. A este propósito diz Marco Aurélio nas Meditaçôes ${ }^{6}$ :

Hás-de ser como uma rocha contra a qual nada podem as ondas todas do mar. Ela está firme e o mar acalma-se em volta dela.

Como exemplo desta corrente filosófica, Marco Aurélio está presente em vários momentos da obra. É o Imperador, o Príncipe e também filósofo, modelo a seguir por todos os magistrados. É o que diz Lúcio ao seu centuriáo Aulo:

Este é o divino Marco Aurélio Antonino, meu e teu senhor. Imaginas o Imperador a perseguir os que lhe atiram epigramas, os que intrigam no palácio, ou os que discordam dele? Marco Aurélio é um filósofo e vive rodeado de filósofos, quando as circunstâncias o não forçam a vestir o elmo e a couraça. O seu procedimento e a sua figura devem iluminar os actos de todos os magistrados do Império, porque são a imagem da moderação e da justiça (100-101).

Dez anos antes de ser duúnviro, Lúcio Valério, ainda jovem, integrou uma delegaçáo de Tarcisis a Roma, a fim de agradecer ao Imperador um donativo de um milhão de sestércios gastos no restauro do forum, das termas e dos templos. Essa estadia coincidiu com o terceiro aniversário do jovem príncipe Lúcio Antonino Cómodo. Enquanto aguardavam ser recebidos pelo Imperador, puderam assistir aos jogos celebrados no Circo Máximo. Lúcio, completamente avesso a estes divertimentos, não apostou nas corridas, notando que o Imperador também não era grande amante destas competiçôes, pois não lhes dispensava muita atenção. A delegação foi, entretanto, recebida e, cumpridas as formalidades protocolares, Marco Aurélio chamou Lúcio pelos seus tria nomina. Disse-lhe que não o vira apostar, deduzindo que ele não gostava daqueles espectáculos, mas fez-lhe uma advertência em tom de conselho que, se viesse a ser seguida por Lúcio, evitaria dissabores no exercício das suas funçóes:

As coisas são como são, Lúcio Quíncio. Suporta-as e abstém-te da indignação. Não se pode impor a cada cidadão um filósofo e seguir-

6 Marco Aurélio, Meditaçōes 4.49. 
-lhe todos os passos. E, sendo, pelo que sei, um jovem promissor na tua cidade, nunca demonstres, por actos ou omissôes, que estás longe do sentir do povo. Poderias romper um equilíbrio fixado na ordem natural das coisas em que as tuas convicçóes interviriam como um mero capricho pessoal, alheio e perturbador (187).

E, um pouco mais adiante, deu-lhe mais um conselho:

Um outro dever do homem público é saber tudo o que se passa à sua volta. Não te esqueças (187).

Lúcio ou não compreendeu ou não quis desviar-se do curso harmonioso de uma vida que se manteve igual a si mesma (recta ratio), não pondo, por isso, em prática os conselhos do Príncipe. Não abdicou de viver segundo a sua natureza, de acordo com a sua opção filosófica, ainda que no exercício da magistratura, deixando para segundo plano o sentir do povo.

Daí a incompreensão, o distanciamento, e até a desilusão que a personalidade de Marco Aurélio provocou na personagem, quando o tribuno Marco Agneio Scauro, chefe das três coortes da VII Legiáo Gémina, estacionada perto das muralhas de Tarcisis, lhe mandou cópia de um édito do Imperador, que obrigava a perseguir todos os cristáos, por os considerar inimigos naturais do império:

Na minha frente, o busto de Marco Aurélio Antonino quase sorria, de olhos levantados ao alto. Pedra, gelado mármore, a contemplar a posteridade, desatento de mim e das minhas súplicas. Como podia um homem táo clemente, tấo ciente da relatividade das coisas e das opinióes, publicar normas assim inflexíveis e arbitrárias? Por que perseguir os cristáos, mais que os mitraicos, os de Cibele, os de Ísis, os de Sóstrato, os Judeus? (...) Por que havia um soberano que eu respeitava e venerava de querer fazer mal a Iunia Cantaber?

Apeteceu-me apostrofar as imagens do Imperador. Voltá-las contra a parede. Retirá-las do meu larário (285).

E, no fim do romance, é indiferente à morte do Imperador:

Desapareceu, por fim, Marco Aurélio Antonino e eu não verti uma lágrima (319). 
Lúcio é fiel aos ideais estóicos, quando, por ocasiāo do seu aniversário, Airhan lhe dá a notícia de que os Mouros passaram o Estreito. Pensativo por uns instantes, resolve dar uma volta por Tarcisis para ver se tudo está bem. Tem uma primeira sensação de estranheza, face à sua cidade, ocupado que andava com o exercício da magistratura:

Cidade afinal estranha, aquela. $\mathrm{Na}$ verdade eu, que todos os dias atravessava Tarcisis e decidia sobre os destinos de Tarcisis, acabava por descobrir que não conhecia a minha cidade... (61).

Mais tarde, quando o senador Calpúrnio lhe chama a atençáo para o seu descuido em relação ao povo, não lhe oferecendo jogos, recorda e nota as palavras coincidentes com os conselhos recebidos dez anos antes, da boca do Imperador:

O que me inquietava, no meu regresso, era perceber que no fundo, os conselhos do senador hispânico Énio Calpúrnio coincidiam, bem vistas as coisas, quase ponto por ponto, com as observações do filósofo Marco Aurélio, dez anos antes...(196).

Como alguém que cai na realidade, que pretende confirmar as acusaçóes de que andava, de facto, alheado do eleitorado, chega a casa nessa noite e pergunta à esposa quem tinha ganho as corridas no Circo Máximo de Roma e o nome do auriga da moda. Mara a tudo responde e a pergunta admirada impóe-se:

- Como sabes, Mara?

- Toda a gente sabe, Lúcio (200).

Mara vai ainda mais longe, ao relatar ao marido que Cornélio Lúculo, um poetastro que tinha sido encontrado morto há algum tempo, enviava poemas a Galla, mulher do centurião, às escondidas, pedindo-lhe encontros. Lúcio, estupefacto, questiona-se sobre se Aulo saberia. Ao que ela responde:

Em Tarcisis toda a gente sabe sempre tudo. Excepto tu, Lúcio Valério...(268).

Um outro aspecto, em que podemos analisar o posicionamento filosófico de Lúcio prende-se com uma ida às termas. Não que precisasse de fazer 
tratamentos, mas táo só para falar com Calpúrnio acerca da necessidade de demolição da casa de Pôncio Módio.

Calpúrnio justifica a sua presença ali, pelas propriedades medicinais das águas:

Hás-de estranhar, ver-me nas termas públicas... O meu médico entende que estas águas são melhores para o sangue. Desde que evite o frigidário, claro...(84).

De facto, deve-se à chegada a Roma de médicos gregos, com uma medicina baseada em métodos científicos, uma utilizaçáo séria e racional das águas. Para a difusão da moda das águas, contribuiu também o influxo do helenismo que havia divulgado na Cidade, juntamente com um ideal de vida muito mais luxuoso que o tradicional, os benefícios para a saúde das curas termais.

É precisamente na época em que se situa o nosso romance, Época imperial que a hidroterapia atinge o seu maior esplendor, ao ser praticada tanto por indivíduos sáos como por doentes. O elevado número dos balnea por todos os pontos do Império Romano demonstra bem como a hidroterapia alcançara uma verdadeira função social: todos frequentavam as termas, fosse qual fosse a época do ano ${ }^{8}$.

Disso nos dá conta o narrador que, antes de entrar nas termas, prevê o ambiente que o espera:

Sabia que ia encontrar nos banhos uma leviandade alegre e despreocupada que fazia contraste com os árduos trabalhos que agora se iniciavam. Era capaz de apostar que a maioria dos da minha cúria, tấo ocupados, achacados e indisponíveis quando se tratava da coisa pública, se encontravam a tagarelar à borda das piscinas (82).

Com esta nota de ironia, Lúcio denuncia a irresponsabilidade de todos os seus colegas, face aos perigos de um iminente ataque dos bárbaros. Por outro lado, remete para o ambiente de certa promiscuidade nos banhos:

7 Sobre as termas, e para informações mais detalhadas, vide Guillén 1977: 329-339; Carcopino 1993: 320-330.

8 Usamos, com a devida vénia, ideias de Carlos Alberto Louro Fonseca, expressas em aulas de seminário e facultadas em apontamentos manuscritos. 
Havia quem, possuindo balneário, nunca aquecesse as fornalhas do hipocausto e preferisse a promiscuidade das termas públicas, ou por uma questáo de avareza ou por apego à convivência (82).

Ecos destas palavras são-nos dados por Marcial que descreve Baias, a mais famosa estância termal da Antiguidade, como sendo o "litoral dou-

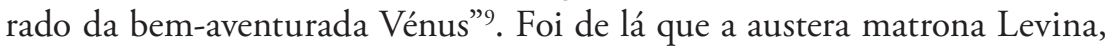
anteriormente uma Penélope, regressara a casa uma Helena, ao abandonar o marido para seguir um jovem por quem se apaixonara ${ }^{10}$. Assim, a vida descuidada e mundana que aí se levava, se, por um lado, tinha um efeito físico e psicológico benéfico sobre aqueles que lá estanciavam, por outro, criava atitudes de rejeição nas pessoas com uma conduta moral mais preconceituosa.

Séneca, filósofo estóico, aconselhava a desviar os próprios passos de um tal lugar, em que a moral corria sérios perigos ${ }^{11}$. Quando descreve ao pormenor o ruído de umas termas vizinhas, o filósofo prefere ignorá-lo, como se fosse algo pouco importante:

Mas, por Hércules, eu não quero saber mais deste frémito do que das ondas ou de uma queda de água... ${ }^{12}$

Desta forma, compreendemos melhor o pouco à-vontade e até a celeridade de Lúcio Quíncio ao entrar nos banhos públicos de Tarcisis:

Não deixei que me vestissem, passei pelo caldário, entre sombras que se moviam preguiçosamente e entrei, de toga, no tepidário, àquela hora apinhado de gente (82).

Queremos, assim, sublinhar o espírito determinado de Lúcio na defesa da sua cidade, contra os inimigos exteriores, não conseguindo, porém,

9 Marcial, Epigramas 11.80.1-2: Litus beatae Veneris aureum Baias / Baias superbae blanda dona Naturae.

10 Marcial, Epigramas 1. 62. 5-6: incidit in flammas: iunenemque secuta relicto / coniuge Penelope uenit, abit Helene.

11 Séneca, Cartas, 5.51.3: Itaque de secessu cogitans numquam Canopum eliget, quamuis neminem Canopus esse frugi uetet, ne Baias quidem: deuersorium uitiorum esse coeperunt. Tradução de Segurado e Campos (1991).

12 Séneca, Cartas a Lucílio, 6.56. 3. Tradução de Rocha Pereira 1994: 228. Vide também Segurado e Campos 1991: 191. 
livrar-se dos inimigos internos, unidos em torno do liberto e candidato a edil, Rufo Glicínio Cardílio. Por outras razões, esses são os mesmos inimigos dos cristáos, onde se destaca Iunia, que como já referi, exerce, desde a primeira hora um profundo fascínio em Lúcio.

\section{Da simbologia dos peixes e das rosas}

Por razões óbvias, o peixe é um elemento presente, desde o princípio até ao fim da história. Sendo os cristãos o grupo catalisador da acção, é lógico que o peixe, um dos símbolos do cristianismo, esteja presente como marca distintiva e de afirmação desse mesmo grupo. A explicação, pelo menos em parte, dessa simbologia é fornecida por Iunia, numa conversa com Lúcio:

- (...) E esse peixe que vocês por aí pintam, o que é?

- Ichtús!

— Eu sei, também falo grego.

- Didacticamente, com uma paciência afectada, explicou-me, a partir das iniciais do vocábulo, que se tratava de um anagrama para Jesus Cristo Filho do Deus Salvador (137).

A palavra grega ixĐúc ('peixe’) foi, portanto, tomada pelos cristãos como um ideograma em que cada uma das cinco letras era vista como a

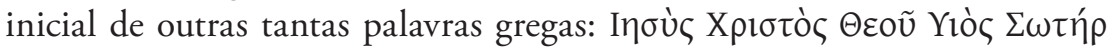
('Jesus Cristo, filho de Deus, Salvador'). Daí as numerosas representaçôes simbólicas do peixe nos antigos monumentos cristãos, nomeadamente funerários ${ }^{13}$. Daí também, e agora já no plano da história, as múltiplas pinturas de peixes, que progressivamente aparecem pelas ruas de Tarcisis:

À minha passagem, notei, em várias paredes, grafitos que representavam um peixe e concluí que a seita adoradora de peixes estava a expandir-se na cidade (109).

Essas pinturas vão aparecer em cima do material de campanha eleitoral do candidato a edil, provocando desde logo uma fractura entre o poder político e o novo grupo religioso, para além de queixas formais ao duúnviro:

13 Chevalier, G.1994: 515-516. 
Um tal Dafino (...) explicou prolixamente que vinham em protesto pedir a minha intervençáo que. Alguém tinha desenhado um peixe sobre os grafitos eleitorais de Rufo Cardílio, o, sobre ser uma afronta ao próprio, assinalava ainda desrespeito ímpio pelas leis e pelos costumes de Roma e da cidade (109-110).

A partir daqui, a fractura acentua-se, a ponto de Lúcio receber uma mensagem anónima com um peixe recortado em couro, que denunciava rituais obscenos, praticados em casa do seu amigo Máximo Sálvio Cantaber. Deste modo, o peixe está lançado no caminho do magistrado: primeiro, porque lhe compete fazer algo para impedir a expansão dessa seita; depois, porque, ao fazer algo, vai ter que se confrontar com Iunia, cabeça do grupo.

A este propósito há um episódio, bastante elucidativo: um dia, Lúcio recebe em sua casa um lúcio (lucius), isto é, um peixe enorme, acompanhado de um saco de favas. Este presente 'envenenado' tinha sido deixado por alguém à entrada da porta. Lúcio não consegue disfarçar alguma apreensão:

Por mais que eu quisesse esquecer-me, ou deixar os cristáos para depois, havia sempre alguém que mos vinha lembrar. Desta vez, através de um simbolismo especioso: um peixe portador do meu nome, devastador e canibal, que engole tudo o que é vivo em volta e que uma vez à solta, é a ruína das lagoas e dos viveiros. E aquele sinal funério das favas...(120-121).

Este sinal premonitório de morte - as favas são símbolo dos mortos e ao mesmo tempo da sua prosperidade ${ }^{14}$ - anuncia desgraça, tragédia. Primeiramente sobre a família de Iunia, depois, pelo menos em parte, sobre Lúcio, que se sente cada vez mais fascinado pela patrícia convertida ao cristianismo, a ponto de, certa vez, ao presidir ao tribunal, dar por si a desenhar um peixe nas tábuas de cera...(140).

Lúcio não pensa converter-se ao cristianismo. Está, antes, rendido a Iunia. Há muito tempo. Quando resolve ir à casa de Máximo falar sobre a denúncia de rituais obscenos, que anonimamente recebeu, dá-se o primeiro encontro entre eles. Não falam, apenas se olham. Lúcio não fica indiferente:

Nessa altura, uma mulher de túnica azul-clara, pregueada à grega, voltou-se na minha direcção. Não sei que impulso foi aquele, se pro-

14 Chevalier, Gheerbrant 1994: 317. 
vocado por uma espontânea impaciência, se por qualquer ruído que, sem querer tivesse produzido. Ao movimento, o sol, passando-lhe nos olhos, de um verde muito esbatido, quase os iluminou num relance brevíssimo. Ela fitou-me por um instante e eu desviei o olhar. (...) Os olhos, quase transparentes àquela luz, dilataram-se, súbitos, e seguiram os meus (128).

A cor dos olhos de Iunia não é inocente. $\mathrm{O}$ verde remete para o reino vegetal, para a natureza, para o despertar da vida, daí a autenticidade com que se apresenta. Para além disso, o verde entra com o vermelho num jogo simbólico de alternâncias. A rosa floresce entre folhas verdes. E é precisamente uma rosa que Clélia, a irmã mais nova de Iunia, deixa dependurada num ramo alto, sob o qual Lúcio e seu pai conversam.

A rosa que ela tinha colocado na árvore caíra sobre o banco de mármore, como um borrão vermelho brilhante, a desfeitar a lisura monótona da pedra...(134).

Aquela rosa, símbolo da atracção por Iunia, eis que se transforma em borrão. Tal como a relaçáo entre os dois, pelo menos a médio prazo.

$\mathrm{Na}$ cidade, a oposição ao grupo de cristãos é cada vez maior. No forum, mais um ajuntamento em torno de Rufo, que arengava, denunciando a pérfida seita, ao mesmo tempo que alguém agitava um cartaz de madeira representando um peixe a debater-se, trespassado por um tridente (157).

Entretanto, mataram os cães a Máximo e Lúcio vê-se compelido a falar com Iunia. Nesse encontro, de novo em casa dela, o magistrado encontra-a no jardim, onde roseiras caóticas que misturam pétalas murchas com pétalas vivas trepavam pelas colunas...(159).

Esta ideia de caos, que é referido numa dimensão exterior, é o reflexo do interior de Lúcio. Contra os seus princípios filosóficos, ele sente-se perturbado pela paixáo:

Logo que vi Iunia, senti estranhamente um baque, uma espécie de sobressalto como se o peito se me contraísse, e esqueci tudo o resto, mesmo a culpa que me moía por ter abandonado as minhas obrigaçóes para comparecer em frente dela (159-160).

É Iunia, apesar do acolhimento frio, que inicia a conversa, desviando-a, no dizer do narrador, para banalidades irritantes: 
Como as rosas tinham crescido em táo pouco tempo, como as noites eram frias em Tarcisis... (160).

Sem querer, Iunia sintetiza a situação: a atracção cresceu em pouco tempo, mas o clima, a conjuntura, constituíam um obstáculo ao seu desenvolvimento. Estes sinais, como que a antecipar o futuro, vêm a confirmar-se.

Quanto às paixões, mais vale não só dominá-las e submetê-las à razão, como até extirpá-las, preconiza o racionalismo moral do estoicismo.

Assim, bem perto do desenlace da intriga, quando Lúcio se viu obrigado a julgar o grupo dos cristãos, eis que o vemos, na véspera do julgamento, em actividades caseiras de relaxe:

Durante quase todo o dia dediquei-me a não fazer nada ou a actividades absolutamente fúteis, como as de transferir peixinhos dourados, raros, do tanque do peristilo para o implúvio ou podar as roseiras do jardim. Nestas tarefas, Mara ajudou-me, com uma alegria fantasiada, por de mais excessiva...(296).

Embora referidas como actividades absolutamente fúteis, estas actividades tinham de ser feitas. Transferir peixinhos e podar rosas são acçōes que carregam uma profunda marca simbólica: como que antecipando o julgamento, os peixinhos, isto é, os cristãos, ou reafirmam a fé e são enviados para Roma para serem condenados à morte (é o que acontece a Iunia), ou a renegam e têm de fazer uma libação à estátua de Júpiter (é o que acontece a todos os outros, Mílquion incluído). $\mathrm{O}$ podar as rosas, na companhia da sua esposa, simboliza a determinação de Lúcio em respeitar a instituição do casamento, em preservar o afecto, o amor em relação a Mara, libertando-o de tudo aquilo que era inútil, que o desfeitava. Só assim ele podia alcançar a imperturbabilidade (apátheia), condição indispensável para atingir a serenidade e ser feliz.

Mara, companheira fiel e cúmplice desta determinação, está alegre. E, para finalizar este dia vivido a dois, escolhe a leitura para antes do adormecer: um trecho do Satyricon ${ }^{15}$ :

15 Petrónio, Satyricon 3.10.: ... sic eloquentiae magistri tamquam piscator, qui nisi eam imposuerit hamis escam quam scierit appetituros esse pisciculos, sine spe praedae moratur in scopulo. (Seguimos a lição de Ernout $\left({ }^{11} 1993\right)$ para o texto latino e usamos a tradução portuguesa de Leão: 2005). 
O mesmo se passa com o mestre de eloquência: se não seguir o exemplo do pescador que coloca na ponta do anzol a isca que sabe que vai atrair os peixitos, lá fica especado no seu rochedo, sem esperança de pescaria.

Bem a propósito este conselho para o duúnviro que, no dia seguinte, qual pescador, vai usar o engodo que sabe ser apreciado pelos ouvintes, ou seja, vai, por fim, satisfazer a vontade dos seus detractores políticos, personificados em Rufo Cardílio, julgando os cristáos. Vai, finalmente, julgar Iunia, que há muito o reclamava, como, aliás se pode comprovar pelas palavras do narrador: ... quando pronunciei a condenação de Iunia à morte (...) olhou para mim, com uma expressão de felicidade triunfal. Nunca lhe tinha visto tanta alegria no rosto (313). Lúcio, por seu turno, liberta-se, finalmente, de uma perturbadora paixão.

É a hora das despedidas. Iunia parte para Roma, Scauro parte com a VII Legião Gémina, Lúcio é aconselhado a partir, pois a sua permanência no duunvirato era malvista por muita gente (316).

E sempre com a mesma determinação, procurando alcançar alguma serenidade perdida, Lúcio resigna ao seu cargo, com a plena sensação do dever cumprido. Preferiu não se despedir de Iunia. Os seus concidadáos preferiram também náo se despedir dele. E lá regressa ao campo, para reconstruir a uilla paterna, reconstruindo uma nova vida. Quanto aos cristãos são fumos fátuos de um lume de palha (319), embora o tenha inquietado, numa das suas deambulaçóes pelo campo, um pequeno escravo que desenhava um peixe na areia.

Pisoteei meticulosamente o desenho com as minhas botinas cardadas...(...). Acto inútil. Não se apagam as realidades destruindo-lhes os símbolos (19).

Neste regresso às origens, longe das intrigas políticas, Lúcio reafirma a fidelidade aos valores da romanidade:

Deixem-me cultivar esta despreocupaçáo, a ilusão de que o mundo seguirá para sempre imperturbado e imperturbável...(...). Sou um senhor da terra, sou um romano, leio, cultivo-me, marco os tempos com o meu porte, (...) o meu trajo togado. Dignidade. Gravidade. Romanidade. Humanidade (16). 
Eis a profissão de fé: imperturbabilidade (apátheia), dignitas, grauitas, Humanitas.

"Como é próprio do Humanismo, o romance postula a perenidade dos valores e sobretudo das inquietaçôes (éticas ou metafísicas) e a contemporaneidade dos Antigos ${ }^{16}$. E, ainda que o autor, numa nota paratextual, avise que este não é um romance histórico ${ }^{17}$, talvez isso seja um apelo a abordarmos, a partir do romance, questôes da actualidade: "e nada - conclui Osvaldo Silvestre - como reflectir sobre o mais bárbaro dos séculos (o nosso) a partir de situaçóes históricas em que bárbaros se encontram às portas da Cidade (quando não a governam, por desencontradas razóes de hereditariedade ou conspiração política)"18.

Em finais do século xx, em que não faltam Rufos Cardílios passeando-se em resplandecentes togas cândidas, ter valores e ser-lhes fiel é uma aprendizagem (ou reaprendizagem) que podemos fazer com os Clássicos. Eis a resposta para quem se continua a perguntar: 'E para que servem, hoje, os Clássicos?’

16 Silvestre 1998: 223

17 Carvalho 1996: 11. Esta nota, em jeito de advertência, aparece antes do capítulo I: «Este não é um romance histórico. Tarcisis, ou, mais propriamente, o município de Fortunata Ara Iulia Tarcisis, nunca existiu». A propósito do conceito de História e suas implicaçóes na obra de Mário de Carvalho, veja-se o artigo de Marinho 1996: 257-267.

18 Silvestre 1998: 219. 


\section{Bibliografia Geral}


(Página deixada propositadamente em branco) 


\section{Ediçôes de Mário de Carvalho}

(21990), Contos da sétima esfera. Lisboa, Caminho.

(1991), Quatrocentos mil sestércios. Lisboa, Caminho.

(71991), Casos do beco das sardinheiras, Lisboa, Caminho.

(31993), A Paixão do Conde de Fróis. Lisboa, Caminho.

(1996), Os Alferes. Lisboa, Caminho.

( $\left.{ }^{3} 1996\right)$, O livro grande de Tebas, Navio e Mariana. Lisboa, Caminho.

(1997), Um deus passeando pela brisa da tarde, Lisboa, Caminho.

$\left({ }^{3} 1997\right)$, Fabulário. Lisboa, Caminho.

(52003), Era bom se trocássemos umas ideias sobre o assunto. Lisboa, Caminho.

(32004), Fantasia para dois Coronéis e uma Piscina. Lisboa, Caminho.

('2006), A inaudita guerra da Avenida Gago Coutinho. Lisboa, Caminho.

(2008), A sala magenta. Lisboa. Caminho.

(2010), A Arte de Morrer Longe. Lisboa, Caminho.

\section{Estudos}

Adorno, T. W. ('1983), "Posição do narrador no romance contemporâneo". In: Benjamin, Honkheimer, Adorno, Habermas. Trad. port. José L. Grünnewald et alii. São Paulo, Abril Cultural: 269-273.

Albaladejo, T. (1986), Teoría de los mundos posibiles y macroestructura narrativa. Alicante, Universidade de Alicante.

Albaladejo, T. (1992), Semántica de la narración: la ficción realista. Madrid, Taurus.

Albérès, R. M. (1972), Métamorphoses du roman. Paris, Albin Michel.

Almeida, J. F. (1997), Bíblia Sagrada. Rio de Janeiro, Fecomex (Ed. Revisada e corrigida).

Alves, C. C. (2010) "Vestígios do trágico em Mário de Carvalho”. Navegaçôes 3. 1: 53-58.

Anacleto, M. T. (1996), “(Sub)versions du "cliché” romanesque au XVII siècle: le "roman bourgeois" de Furetière”, Confluências 14: 97-109.

Angelini, P. R. K. (2011) "Recensão de Carvalho, M. A arte de morrer longe. Lisboa, Caminho, 2010. 128p.”. Navegaçōes 4. 1: 131-133.

Arnaut, A. P. (2001), "Donas e donzelas n'a Demanda do Santo Graal”, Santa Barbara Portuguese Studies. Califórnia, n. 5: 29-71. 
Aristófanes (21989), A Paz. Tradução de Silva. M. F. Coimbra, Instituto Nacional de Investigação Científica.

Aristófanes (2006), As Aves. Tradução de Silva, M. F. Lisboa, Edições 70.

Aristóteles (1986), Poética. Tradução de E. Sousa. Lisboa, Fundação Gulbenkian.

Arnaut, A. P. (2002), Post-Modernismo no romance português contemporâneo. Fios de Ariadnemáscaras de Proteu. Coimbra, Almedina.

Assis, A. K. T. (2008), Arquimedes, o centro de gravidade e a lei da alavanca. Montreal, Apeiron Montral.

Auerbach, E (1976), Mimesis (A representação da realidade na literatura ocidental). São Paulo, Perspetiva [1 $1^{\text {a }}$ ed., 1946].

Aurélio, Marco (1971), Pensamentos. Versão de João Maia. Lisboa, Editorial Verbo.

Bakhtine, M. (1970), La Poétique de Dostoievsky. Paris, Éd. du Seuil.

Bakhtine, M. (1981), Dialogic imagination: four essays. Austin, University of Texas Press.

Bakthine, M. (1981), Problemas da poética de Dostoievski. Trad. port. Paulo Bezerra. Rio de Janeiro, Ed. Forense-Universitária.

Benjamin, W. (1985), "Sobre o conceito de História. Tradução de Sérgio Paulo Rouanet”. In: Obras escolhidas. Magia e técnica, arte e política. São Paulo, Editora Brasiliense: 222-232.

Bessière, J. (2010), Le roman contemporain ou la problemacité du monde. Paris, PUF.

Beye, C. R. (1964), "Homeric battle narrative and catalogues", Harvard Studies in Classical Philology 68: 345-373.

Bergson, H. (2001), O riso: ensaio sobre a significação da comicidade. Trad. port. Ivone C. Benedetti. São Paulo, Martins Fontes.

Bhabha, H. K. (1998), O local da cultura. Belo Horizonte, Editora UFMG.

Bianchet, S. B. (2004), Petrônio. Satyricon. Edição bilíngüe. Belo Horizonte, Crisálida.

Bougnoux, D. (1991), "Le principe d'identification”. In Personnage et Histoire Littéraire. Toulouse, Presses Universitaires du Mirail: 187-195.

Brandão, J. L. (2001), A poética do Hipocentauro: Literatura, sociedade e discurso ficcional em Luciano de Samósata. Belo Horizonte, Ed. UFMG.

Brasete, M. F. (2003), “A crítica às mulheres no fr. 7 de Semónides de Amorgos”. In: Mora, C. M. (ed.), Sátira, Paródia e Caricatura: da Antiguidade aos nossos dias. Aveiro, Universidade de Aveiro: 39-56.

Brauner, E. F. (2009), “" Era bom que trocássemos umas ideias sobre o assunto”: ironia de um narrador e discussão do romance", Revista Electrónica de critica e teoria de literaturas. Dossiê: o romance português e o mundo contemporâneo 5. 2. Porto Alegre: 1-9.

Buescu, H. (1995), A Lua, a Literatura e o Mundo. Lisboa, Cosmos. 
Buescu, M. L. C. (1979), Aspectos da herança clássica na cultura portuguesa. Lisboa, Instituto de Cultura Portuguesa.

Camôes, L. (1979), Os Lusíadas. Prefácio de Hernâni Cidade. São Paulo, Abril Cultural.

Carcopino, J. (1993), La vida cotidiana en Roma en el apogeo del imperio, trad. esp. Madrid, Ediciones Temas de Hoy.

Cardoso Bernardes, J. A. (1988), O Bucolismo Português. A égloga do Renascimento e do maneirismo. Coimbra, Livraria Almedina.

Carvalho, M., (2003), "Mário de Carvalho: crónica do aturdimento". JL - Jornal de Letras, Artes e Ideias 864, 12/11: 12.

Ceia, C. (2007), A Construção do romance (Ensaios de literatura comparada no campo dos estudos anglo-portugueses). Coimbra, Almedina.

Chevalier, J., Gheerbrant, A. (1994), Dicionário dos Símbolos, trad. port., Lisboa, Editorial Teorema.

Colaço, J. (1995), “Mário de Carvalho”, Biblos. Enciclopédia verbo, I, s.u.

Compagnon, A. (2001), O demônio da teoria: Literatura e senso comum. Belo Horizonte, Editora UFMG.

Constâncio, N. (2007), Ruinas e incertezas em "Um Deus passeando pela brisa da tarde”, de Mário de Carvalho. Lisboa, Edições Colibri.

Costa, L. S. (1995), “Era Bom que Trocássemos Umas Ideias Sobre O Assunto, de Mário de Carvalho. A Arquitectura, A Violência”. In: Público/Leituras, 11 de Novembro:10.

Cotrim, J. P. (1996), Entrevista a Mário de Carvalho: "Alguma coisa me perturba”. Ler/Livros e Leitores 34: 45.

Cotrim, J.P. (1996), "Mário de Carvalho. O Mistério da Literatura”, entrevista ao autor. LER 34, Primavera.

Cristóbal, V. (1992), "Búsqueda de campo, hastío de ciudad. Pasión antigua y contemporánea”. In: Guzmán, A. et alii (ed.), Aspectos modernos de la Antigüedad y su aprovechamiento didáctico. Madrid, Ediciones Clásicas: 131-143.

Davison, M. (1976), "The thematic use of ekphrasis in the ancient novel”, in Erotica antiqua. Acta of the International Conference on the Ancient Novel. Bangor, ICAN: 32-33.

Devereux, G. (1975), Dreams in Greek tragedy. Oxford, Basil Blackwell.

Dijksterhuis, E. J. (1987), Archimedes. Translated by C. Dikshoorn. Princeton University Press.

Diogo, A. A. L. (1997), "Exórdio". In: Biblos- Enciclopédia Verbo das Literaturas de Lingua Portuguesa. Lisboa, São Paulo, Verbo.

D’Onofrio, S. (1978), Poema e Narrativa: estruturas. São Paulo, Duas Cidades. 
Duncan, T.S. (1935), “The deus ex machina in Greek Tragedy”. Philological Quarterly 14: $126-141$.

Dunn, F. M. (1985), Euripidian Endings: a Study of the Choral Exit, the Action, the Concluding Prophecy and the Deus ex Machina. Yale University: 111-167.

Eco, U. (1979), Leitura do Texto Literário. Lector in Fabula. Trad. Mário Brito. Lisboa, Presença.

Entrevista com Mário de Carvalho http://www.homemmag.pt/pt/index.php/arte-e-literatura/arquivo-arte-literatura/87-luisa-costa-gomes-entrevista-mario-de-carvalho

Ernout, A. ( $\left.{ }^{11} 1993\right)$, Pétrone. Le Satyricon. Paris, Les Belles Lettres.

Ernout A, Meillet, A. ( $\left.{ }^{4} 1967\right)$, Dictionnaire etymologique de la langue latine: histoire des mots. Paris, Librairie C. Klincksieck.

Errandonea, I. (1954), Diccionario del mundo clásico. Barcelona, Editorial Labor.

Eschilo ( $\left.{ }^{4} 2000\right)$ I sette contro Tebe. Con testo a fronte. Introd. Umberto Albini. Trad. Ezio Savino. Milano, Garzanti Editore.

Feijóo, B. (1998), Um Não Sei Quê. Lisboa, Vega [1746].

Ferreira, C. (2003), “Mário de Carvalho. A arte de bem iludir o leitor”. In: Rodapé: 45-51.

Ferreira, P. S. (1999), “A paródia e as suas implicações didácticas”. In: Torrão, J. M. N. (ed.), III Colóquio Clássico - Actas. Aveiro, Universidade de Aveiro: 113-137.

Ferreira, P. S. (2000), Os elementos paródicos no Satyricon de Petrónio e o seu significado. Lisboa, Colibri.

Ferreira, P. S. (2003), “Paródia ou paródias?”. In: Mora, C. M. (ed.), Sátira, Paródia e caricatura: da Antiguidade aos nossos dias. Aveiro, Universidade de Aveiro: 279-300.

Fialho, M. C. (1992), Luz e trevas no teatro de Sófocles. Coimbra, Instituto Nacional de Investigação Científica.

Figueiredo, M. N. (2006), "Com humana crueldade se tece um conto. A propósito de Homenagem ao Papagaio Verde”. In: Santos, G. (ed.) Jorge de Sena: Ressonâncias e Cinqüenta Poemas. Rio de Janeiro, 7Letras.

Fowler, D. P. ((1991), "Narrate and describe: the problem of ecphrasis", Journal of Rhetorical Studies 81: 25-35.

Frow, J. (1986), “Spectacle Binding: On Character”. Poetics Today 7. 2: 227-250.

Gaffiot, F. (1934), Dictionnarie Illustré Latin-Français. Paris, Librairie Hachette.

Garrett, A. (1973), Viagens na minha Terra. Rio de Janeiro, Editora Três.

Genette, G. (1972), Figures III. Paris, Ed. du Seuil.

Gennete, G. (1997), L'Cuvre de l'Art. La Relation Esthétique, II. Paris, Ed. du Seuil.

Genette, G. (2004), Métalepse. Paris, Ed. du Seuil.

Gomes da Torre, M. (1992), “Acerca da tradução da metáfora”. Linguas e Literaturas 9: 209-226. 
Grimal, P. (s/d), Dicionário de Mitologia Grega e Romana. Lisboa.

Guillén, J. (1977), Vrbs Roma - vida e costumbres de los romanos, vol. I: La vida privada. Salamanca, Ediciones Sígueme.

Guthrie, W. K. C. (1976), Les Sophistes. Paris, Payot.

Halliwell, S. (1968), Aristotle's Poetics. Chicago and London.

Hamon, P. (1976), “O que é a descrição?”. In: Seixo, M. A. (ed.), Categorias da narrativa. Lisboa, Arcádia: 61-83.

Hardwick, L. (2003), Reception Studies. Greece and Rome. New Surveys in the Classics. Oxford, Oxford University Press. [recensão do livro por Martin M. Winkler, in Bryan Mawr Classical Review 2004].

Heródoto. (2002), Histórias. Livro I. Tradução de Ferreira, J. R., Silva, M. F. Lisboa, Ediçóes 70. Heródoto (1997), Histórias. Livro III. Tradução de Silva, M. F., Abranches, C. Lisboa, Ediçóes 70. Heródoto (2000), Abranches, C., Histórias. Livro IV. Tradução de Silva, M. F., Abranches, Lisboa, Edições 70.

Homero (2003), Odisseia. Tradução de Frederico Lourenço. Lisboa, Livros Cotovia.

Homero (2005), Ilíada. Tradução de Frederico Lourenço. Lisboa, Livros Cotovia.

Hoorn, J. F., and Konijn, E. A. (2003), "Perceiving and experiencing fictional characters: An integrative account”. Japanese Psychological Research 45. 4: 250-268.

Horácio (1975), Arte Poética. Tradução de R. M. R. Fernandes. Lisboa, Clássica Editora.

Hutcheon, L. (1977), “Modes et formes du narcisisme littéraire”. Poétique 29: 90-106.

Hutcheon, L. (1984), Narcissistic Narrative. The Metafictional Paradox. New York and London, Methuen.

Hutcheon, L. (1985), A Theory of Parody. The Teachings of Twentieth Century Art Forms. New York \& London, Methuen; (1989), Uma teoria da paródia, trad. port. Lisboa, Ediçóes 70.

Hutcheon, L. (1988), A poetics of Postmodernism. History, Theory, Fiction. New York/London, Routledge; (1991), Poética do Pós-Modernismo. Trad. Ricardo Cruz. Rio de Janeiro, Imago.

Hutcheon, L. (2000), Teoria e Política da Ironia. Trad. port. Julio Jeha. Belo Horizonte, Editora UFMG.

Immerwahr, H. R. (1966), Form and thought in Herodotus. University of North Carolina.

Izaac, H. J. ( ${ }^{3} 1969$, 1973), Martial. Épigrammes, I-II. Paris, Les Belles Lettres.

Jauss, H. R. (1986), Experiencia y Hermeneutica Literaria. Ensayos en el campo de la experiencia estétca. Madrid, Taurus, [1977].

Jenny, L. (1979), "A estratégia da forma”, Poétique. Revista de teoria e análise literárias. Trad. port. Clara C. Rocha. Coimbra, Almedina: 5- 49. 
Jerome, K. J. , “Three men on the Brummel'. In: http://www.gutenberg.org/catalog/world/ readfilefk_files $=2061881$

Jourdan, P. (1996), "Paul Valéry chasseur de perroquets", Confluências 14: 51-59.

Júdice, N. (1997), Viagem por um século de Literatura Portuguesa. Lisboa, Relógio d'Água.

Julien, Y. (1998), Aule-Gelle. Les nuits attiques, IV. Paris, Les Belles Lettres.

Jurado, F. G. (1999), "Apuntes para una historia prohibida de la literatura latina en el siglo XX: La voz de los lectores no académicos”. In: Morán, M. C. A.; Iglesias Montiel, R. M. (eds.), Contemporaneidad de los clásicos en el umbral deI tercer milenio. Actas deI Congreso Internacional Contemporaneidad de los clásicos: La tradición greco-latina ante el siglo XXI. La Habana, Universidad de Murcia: 77-85.

Kerferd, G. B. (2003), O movimento sofista. Trad. port. Margarida Oliva. São Paulo, Ediçôes Loyola.

Kirk, D. M. (1960), The digression, its use in prose fiction from the Greek romance through the eighteenth century. Stanford University.

Kristeva, J. (1974ª), Introdução à semanálise. São Paulo, Perspectiva.

Kuester, M. (1992), Framing Truths - Parodic Structures in Contemporary English-Canadian Historical Novels. Toronto/London, Toronto University Press.

Lausberg, H. (1963), Elementos de retórica literária. Trad. port. Raul M. Rosado Fernandes, Lisboa, Gulbenkian.

Leão, D. F. (1996), “Trimalquião: a humanitas de um novo-rico”. Humanitas 48: 161-182.

Leão, D. F. (1997), “Trimalquião à luz dos Caracteres de Teofrasto”. Humanitas 49: 147-167.

Leão, D. F. (1998), As Ironias da Fortuna. Sátira e Moralidade no Satyricon de Petrónio. Lisboa, Colibri.

Leão, D. F. (2004), “Zoilo e Trimalquião, duas variaçôes sobre o tema do novo-rico”. Humanitas 56: 191-208.

Leão, D. F. (2004a), “O Satyricon de Petrónio e a crise dos paradigmas tradicionais”. In: Nascimento, A. (ed.), Antiguidade Clássica: Que fazer com este património?. Lisboa, Centro de Estudos Clássicos: 233-242.

Leão, D. F. (2005), Petrónio. Satyricon. Lisboa, Cotovia.

Lepaludier, L (2002), Métatextualité et métafiction. Théorie et analyses, Presses Universitaires de Rennes, CRILA.

Levi, P. (1988), É isto um homem? Rio de Janeiro, Rocco.

Lévy, E. (1983), "Le théâtre et le rêve: le rêve dans le théâtre d'Eschyle", in Zehnacker, H. (ed.), Théatre et spectacles dans l'Antiquité. Actes du Colloque de Strasbourg. Leiden: 141-168.

Lopes, S. R. (2003), Literatura, Defesa do atrito. Lisboa, Copiart. 
Lourenço, E. ('1982), "Da literatura como interpretação de Portugal”. In O Labirinto da Saudade (Psicanálise Mitica do Destino Português). Lisboa, D. Quixote: 85-126.

Lourenço, F. (2003), Homero. Odisseia. Lisboa, Cotovia.

Luciano (1996), Uma história verídica. Tradução de C. Magueijo. Lisboa, Editorial Inquérito Limitada.

Lukács, G. (1989), Théorie du roman. Paris, Flammarion [1916].

"Na Lusitânia com Mário de Carvalho (História, paródia e ironia em Quatrocentos mil sestércios e Um deus passeando pela brisa da tarde)". In Veredas 5 (2002) 211-224.

Macedo, A. G. (2008), Narrando o pós-moderno: reescritas, revisôes, adaptaçôes. Braga Universidade do Minho.

Machado, J. P. (1995), Dicionário etimológico da Língua Portuguesa. Lisboa, Livros Horizonte.

Malina D. (2002), Breaking the frame: metalepsis and the construction of the subject. Columbus, Ohio State UP.

Margolin, U. (2005), “Character”. In: Herman, D., Jahn M., Ryan, M.-L. (eds.), Routledge Enciclopedia of Narrative Theory. London/New York, Routledge: 54-57.

Marinho, M. F. (1996), "O sentido da história em Mário de Carvalho", Revista da Faculdade de Letras. Linguas e Literaturas: 257-267.

Marinho, M. F. (2010), "À la recheche de l'identité perdue. Essai sur la crise d'identité dans le roman portugais contemporain”. In: Besse, M. G. \& Ralle, M. (eds.), Les Grands Récits: Miroirs Brisés? Paris, Índigo:186-198.

Martin, F. (1987), Les mots latins. Paris, Hachette.

Martins, J. C. O. (2011), "Mário de Carvalho e a reflexão metaficcional sobre o futuro do romance”. Diacrítica. Dossiê Literatura e Religiāo 25/3: 23-44.

Martins, J. C. O. (2011), “Pensar Portugal - ironia, paródia e desencanto: Mário de Cavalho e o retrato melancólico de um país". In: Carvalho da Silva, J. A., Martins, J. C. O., Gonçalves, M. (eds.), Pensar a Literatura no Séc. XXI. Braga, Univ. Católica Portuguesa: 463-478.

Martins, J. C. O. (s.d.), "La barbarie de l'ignorance dans la culture postmoderne et la fiction de Mário de Carvalho". In: De l'Extrême: pratiques du contemporain dans les mondes ibériques et ibéro-américains, Paris, CRIMIC [em publicação].

Martins, M. F. (1983), Sombras e transparências da literature. Lisboa, INCM.

Martins, Maria João (2003), "Mário de Carvalho: crónica de um aturdimento" [entrevista], JL - Jornal de Letras, Artes e Ideias, no 864, 12 novembro, p. 12.

Mead, G. (1990), “The Representation of Fictional Character”. Style 24. 3: 440.

Medeiros, W. (1997), "Do desencanto à alegria: o Satyricon de Petrónio e o Satyricon de Fellini”. Humanitas 49: 169-175. 
Melanda, P. C. O. (2001), Pela mão de Clio. A reescrita da História em Mário de Carvalho. Aveiro. 38. Dissertação de Mestrado em Estudos Portugueses, apresentada à Universidade de Aveiro. Exemplar em CDRom.

Melero Bellido, A. (2001), "La utopia cómica o los límites de la democracia”, Cuadernos de Literatura Griega y Latina 3: 7-25.

Melero Bellido, A. (2004), "La lengua de la utopia". In: López Eire, A., Guerrera, A. R. (Eds.). Registros Lingüísticos en las lenguas clásicas. Salamanca, Ediciones Universidad Salamanca: 149-172.

Mendes, A. M. G. (1999), "Cultura clássica em Um Deus Passeando pela brisa da tarde de Mário de Carvalho”, III Colóquio Clássico - Actas, Aveiro: 347-363.

Mendes, A. M. G. (2005), “Trimalquião, os coronéis e a piscina: retrato impiedoso de um país em crise”. Ágora. Estudos Clássicos em Debate. Aveiro 7: 129-150.

Mendes, J. P. (1997), Construção e Arte das Bucólicas de Virgílio. Coimbra, Almedina.

Mendonça, F. (1997), “A Paixão do Conde Fróis”. Colóquio/Letras 99. Setembro-Outubro.

Mexia, P. (2005), “O Manuel Germano”. Diário de Notícias. Artes, 17 de Junho: http:// dn.sapo.pt/2005/06/17/artes/o_manuel_germano.html

Moisés, M. ('1973), A criação literária: introdução à Problemática da Literatura. São Paulo, Melhoramentos.

Mora, C. M. (2003), “A outra resposta de Tirésias”. In: Mora, C. M. (ed.), Sátira, Paródia e caricatura: da Antiguidade aos nossos dias. Aveiro, Universidade de Aveiro: 7-13.

Morais e Silva, A. (1953), Grande Dicionário da Lingua Portuguesa. Lisboa, Confluência.

Mourão, J. A. (1998), "Posfácio”, a Feijóo, Benito - Um Não Sei Quê. Lisboa, Vega.

Nickel, R. (1999), “Lucian's True Story: impressions of a fancy voyage”, Euphrosyne 27: 249-257.

Niederauer, S. (2008), "Era bom que trocássemos umas ideias sobre o assunto ou $\mathrm{O}$ simulacro da narrativa na pós-modernidade”. Letras de Hoje 43. 4: 83-88.

Oliveira, B. S. (1997), Eurípides. Hipólito. Brasília, Editora UNB.

Onelley, G. B. (2004), “A resistência da nau: cidade na luta pelo poder”. Calíope 12: 33-42.

Otte, G. (1996), "Rememoração e citação em Walter Benjamin". Revista de Estudos de Literatura 4. Belo Horizonte, Centro de Estudos Literários (CEL), Faculdade de Letras da UFMG: 211-223.

Pereira, E. (2003), "Viagens na minha terra: ciladas da representação". Revista do Centro de Estudos Portugueses 23 n. 32: 61-68.

Pereira, S. M. (2008), “Poética dos sonhos e das visōes em estado de vigília - I”, Humanitas 60: 11-28.

Pereira, S. M. (2009), "Poética dos sonhos e das visōes em estado de vigília - II”, Humanitas 61: 5-18.

Perelman, C. O. (1993), O Império Retórico: Retórica e Argumentação. Tradução de Fernando Trindade e Rui Alexandre Grácio. Porto, Ediçóes Asa. 
Perrin-Naffakh. A.-M. (1996), "Le langage cliché: aveu d'usure ou pouvoir d'écho". Confluências 14: 7-14.

Perrone-Moisés, L. (1979), “A intertextualidade crítica”. Poétique. Revista de teoria e análise literárias. Trad. port. Clara C. Rocha. Coimbra, Almedina: 209-230.

Pimentel, C. S. (2001), "O latim nas literaturas portuguesa e francesa: instrumentos, métodos e agentes de ensino”, Ágora, Estudos Clássicos em Debate 3: 183-185.

Piwnik, M.-H. (1998), "Mário de Carvalho: crónica de um desfecho anunciado", Veredas 1, Porto: 317-325.

Piwnik, M.-H. (2004), “De Sienkiewicz a Mário de Carvalho: Duas construções da História”. In: Literatura e História. Actas do Colóquio Internacional, Porto, vol. II: 139-144.

Platão ( $\left.{ }^{12} 2010\right)$, República. Trad. Maria Helena da Rocha Pereira. Lisboa, Fundação Calouste Gulbenkian.

Préchac, F. (1987), Sénèque. Lettres a Lucilius, II. Paris, Les Belles Lettres.

Queirós, E. de (s./d.), Os Maias. Lisboa, Livros do Brasil.

Queirós, E. de (2000), O Crime do Padre Amaro. Ed. crítica de Carlos Reis e M. Rosário Cunha. Lisboa, IN-CM.

Rabaté, E. (1996), "Henri Michaux et le cliché: résistance et fascination”. Confluências 14: 61-75.

Raimond, M. (1989), Le Roman. Paris, Armand Colin.

Reis, C. (1996), "Mário de Carvalho. Incitação ao romance”. Jornal de Letras 28 Agosto: 22-23.

Reis, C. (1997), "Fábula”. In: Biblos-Enciclopédia Verbo das Literaturas de Lingua Portuguesa. Lisboa, São Paulo, Verbo: 462-463.

Reis, C. (2005), História crítica da literatura portuguesa, vol. IX (Do neorrealismo ao postmodernismo). Lisboa, Verbo: 287-318.

Reis, C., Macário Lopes, A. C. (72007), Dicionário de narratologia. Coimbra, Almedina.

Ricoeur, P. (1983), Temps et Récit. T.I. Paris, Ed. du Seuil.

Rio Torto, G. M. (1996), "Linguagem e clichê", Confluências 14: 159-175.

Robilliard, M.-A. (2002), Água em pena de pato de Mário de Carvalho. Um teatro do desencanto. Trad. port. Manuel Ruas. Lisboa, Editorial Caminho.

Rocha Pereira, M. H. (1955), Concepçōes Helénicas de felicidade no além: de Homero a Platão. Coimbra, Maranus.

Rocha Pereira, M. H. (1980), Poesia Grega Arcaica. Coimbra, Instituto de Estudos Clássicos.

Rocha Pereira, M. H. (1984), Estudos de História da Cultura Clássica, vol. II (Cultura Romana). Lisboa, Fundação Calouste Gulbenkian.

Rocha Pereira, M. H. ('1994), Romana - Antologia da Cultura Latina. Coimbra, Universidade de Coimbra. 
Rocha Pereira, M. H. ( $\left.{ }^{10} 2006\right)$, História da Cultura Clássica, I (Cultura Grega). Lisboa, Fundação Calouste Gulbenkian.

Rodrigues, L. G. (2005), “A Radioestesia”. In http://rprecision.logspot.com/2005/06/radiestesia.html Rose, M. A. (1979), Parody and meta-fiction. London, Croom Helm.

Sant'Anna, A. R. ('1985), Parodia, paráfrase \& cia. São Paulo, Ática.

Santos, R. B. (2009), Aspectos da Herança Clássica em Mário de Carvalho. Belo Horizonte, Faculdade de Letras da UFMG, 2009. [versão policopiada].

Saramago, J. (1989), História do Cerco de Lisboa. Lisboa, Caminho.

Saramago, J. (1990), "História e Ficção”. Jornal de Letras, Artes e Ideias, 6 de Março.

Schaeffer, J. M. (1992), L'art de l'àge moderne. L'esthétique et la philosophie de l'art du XVIIIème siècle à nos jours. Paris, Gallimard.

Schmidt, W. (1963), Der Deus Ex Machina bei Euripides. Tübingen University.

Schwartz, J. (1981), Murilo Rubião: A poética do Uroboro. São Paulo, Editora Ática.

Scodel, R. (1999), Credible impossibilities. Conventions and strategies of verisimilitude in Homer and Greek tragedy. University of Michigan Press.

Sedlmayer, S., "Sinais de fogo, aviso de incêndio: ideias estéticas, históricas e literárias em Jorge de Sena e Walter Benjamin”. In: Revista Literatrua e Autoritarismo. Dossiê Walter Benjamin e a Literatura brasileira. Santa Maria, Universidade Federal de Santa Maria/ RS. Disponível em http://w3.ufsm.br/grpesqla/revista/dossie05/art_02.php

Seel, M. (1992), "Le langage de l'art est muet". In: Bouchindhomme, Ch., Rochlitz, R. (eds.), L'art Sans Compas. Redéfinitions de l'Esthétique. Paris, Éd. du Cerf.

Segurado e Campos, J. A. (1991), Cartas a Lucílio, Lisboa, Fundação Calouste Gulbenkian.

Seixo, M. A. (1995), "Mário de Carvalho. Romance, Humanismo e BD”, JL - Jornal de Letras, Artes e Ideias, 12. 4: 24-25.

Sena, J. http://www.letras.ufrj.br/lerjorgedesena/port/antologia/ficcao-e-teatro/texto.php?id=319

Sequeira, M. G. R. (1996), Aproximação a uma Leitura do Risivel em A Paixão do Conde de Fróis. Tese de Mestrado apresentada à Faculdade de Letras da Universidade do Porto (dact.).

Settis, S. (2006), El futuro de lo 'clásico'. Traducción de Andrés Soria Olmedo. Madrid, Abada Editores.

Silva, M. F. (1987), Critica do teatro na comédia antiga. Coimbra, INIC.

Silva, M. F. (2005), Ensaios sobre Euripides. Lisboa, Cotovia.

Silva, M. F. (2007), "A porta na comédia de Aristófanes: uma entrada para a utopia”. In: Ensaios sobre Aristófanes. Lisboa, Cotovia: 257-274. 
Silva, M. F. (2008), "Mensagens, cartas e livros no teatro grego antigo", in Matos, M. C. (ed.), Helénicos. Estudos em homenagem do Prof. Jean-Pierre Vernant (1914-2007). Lisboa, Ediçôes Távola Redonda: 227-260.

Silva, M. F. (2009), Utopias e distopias. Coimbra, Imprensa da Universidade.

Silvestre, O. M. (1998), "Mário de Carvalho: Revolução e Contra-revolução ou um passo atrás e dois à frente”. Colóquio/Letras 147/148: 209-229.

Silvestre, O. e Diogo, A. L. (1998), "Entrevista a Mário de Carvalho", in <http://www. ciberkiosk.pt>, arquivo, $\mathrm{n}^{\circ} 1$ (15 pp.).

Simões, M. J. (2006), “Atrevidas e desbordantes: as personagens em Mário de Carvalho”. In Figuras da Fiç̧ão. Coimbra, Centro de Literatura Portuguesa: 79-92.

Spivak, G. Ch. ('2003), “Can the subaltern speak?” In: Asheroft, B., Griffith, G., Tiffin, H. (eds.), The post-colonial studies reader. New York, Routledge.

Spivak, G. Ch. (1998), "Puede hablar elsujeto subalterno?”. Orbis Tertius 3. 6: 1-44.

Sterne, L. (1860), The Works of Lawrence Sterne. London, Henry Bohn.

Thomasson, A. (2003), "Fictional Characters and Literary Practices". British Journal of Aesthetics 43. 2, April:138-157.

Todorov, T. (1999), O homem desenraizado. Trad. Christina Cabo. Rio de Janeiro, Record.

Torrão, J. M. N. (ed.) (1999), III Colóquio Clássico. Aveiro, Universidade de Aveiro.

Tosi, R. (2000), Dizionario delle sentenze latine e greche. Milano, Biblioteca Universale Rizzoli.

Trindade, L. (2004), “Os excessos de Abril”, História 65: 20-31.

Valente, A. M. (2004), Aristóteles. Poética. Lisboa, Gulbenkian.

Várzeas, M. (2001), Silêncios no teatro de Sófocles, Lisboa, Cosmos.

Villeneuve, F. (1970), Horace. Odes et Epodes, I. Paris, Les Belles Lettres.

Xavier, L. G. (2007), O discurso da ironia. Lisboa, Novo Imbondeiro.

Walton, K. (1990), Mimesis as Make-Believe: On the Foundations of the Representational Arts. Cambridge Mass., Havard University Press.

Waugh, P. (2003), Metafiction. The Theory and Practice of Self-Conscious Fiction. London \& New York, Routledge [1984].

Wesseling, E. (1991), Writing History as a Prophet. Postmodernist Innovations of the Historical Novel. Amsterdam/Philadelphia, John Benjamins.

Wolff, F. (2004), “Quem é bárbaro?”. In: Novaes, A. (ed.), Civilização e Bárbarie. São Paulo, Companhia das Letras: 19-43.

Woods, J. (1974), The Logic of Fiction. Paris, Mouton; (2010), A Mecânica da fiç̧âo. Lisboa: Quetzal. Zagajewski, A. (2003), En la belleza ajena, trad. esp. A. E. Diaz-Pintado Hilario, Valencia, Pre-Textos. 